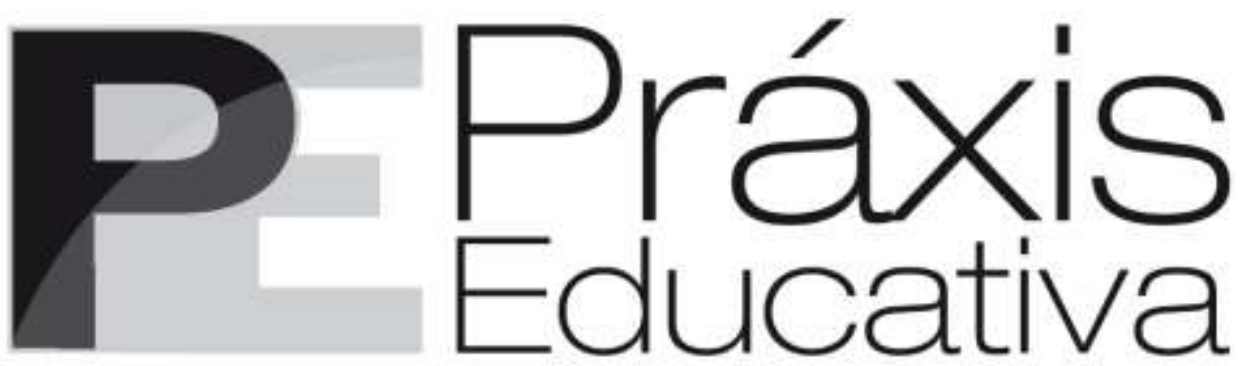

ISSN 1809-4031

elSSN 1809-4309

https://doi.org/10.5212/PraxEduc.v.17.20018.022

Seção: Tradução

\title{
O que é agenciamento de políticas?*
}

\section{What is policy assemblage?}

\section{¿Qué es agenciamiento de políticas?}

\author{
Glenn C. Savage ${ }^{* *}$ \\ http://orcid.org/0000-0001-6495-6798
}

\begin{abstract}
Resumo: A teoria sobre agenciamento explodiu na pesquisa sobre políticas, especialmente entre os pesquisadores que trabalham na área de mobilidade e buscam aproveitar o potencial dessa abordagem para entender como as políticas se movem, mudam e se manifestam em contextos cada vez mais transnacionais. A ubiquidade do agenciamento, no entanto, nem sempre o torna preciso, sendo o conceito definido de forma variada e, às vezes, carente de força conceitual e poder explicativo. Este artigo busca conceituar e defender uma abordagem sobre o agenciamento para análise de políticas. Ao sintetizar os eixos centrais da literatura existente, identifica três fundamentos teóricos e conceituais centrais para uma abordagem sobre o "agenciamento de políticas": (1) relações de exterioridade e emergência; (2) heterogeneidade, relacionalidade e fluxo; e (3) atenção ao poder, política e agência. Juntos, esses fundamentos sinalizam uma coerência para a teoria do agenciamento e sugerem uma abordagem com um poderoso potencial, permitindo que os pesquisadores vejam e expliquem as coisas de maneiras que muitas tradições estabelecidas na pesquisa de políticas não conseguem. Ao identificar os fundamentos e oferecer exemplos de como cada um pode ser mobilizado, o artigo fornece o início de um arcabouço teórico ainda não articulado de forma sistemática para a pesquisa sobre agenciamento de políticas, convidando, assim, a uma discussão mais aprofundada sobre o que significa realizar este tipo de trabalho.
\end{abstract}

Palavras-chave: Agenciamento. Políticas públicas. Mobilidade. Poder.

Abstract: Assemblage thinking has exploded in policy research, especially among scholars working in the policy mobilities field who are seeking to harness the potential of an assemblage approach to understand how policies move, mutate and manifest in increasingly transnational contexts. The ubiquity of assemblage, however, does not always render it clear, with the concept being variously defined and sometimes lacking conceptual strength and explanatory power. This paper seeks to conceptualize and defend an assemblage

\footnotetext{
* A versão original deste artigo em inglês foi publicada em Territory, Politics, Governance, v. 8, n. 3, p. 319-335, 2020. O artigo foi traduzido e publicado com a permissão da Taylor \& Francis, do editor do periódico, da Regional Studies Association e do autor, aos quais agradecemos. Tradução de Samuel Molina Schnorr (Universidade de Brasília -UnB). Revisão Técnica de Thiago Ranniery (Universidade Federal do Rio de Janeiro - UFRJ).

** Professor Associado do Department of School of Social Sciences na University of Western Australia, Australia. E -mail: <glenn.savage@uwa.edu.au>.
}

Práxis Educativa, Ponta Grossa, v. 17, e2220018, p. 1-21, 2022 Disponível em: <https://revistas2.uepg.br/index.php/praxiseducativa $>$ 
approach to policy analysis. By synthesizing core threads from existing literature, it identifies three theoretical and conceptual foundations central to a 'policy assemblage' approach: (1) relations of exteriority and emergence; (2) heterogeneity, relationality and flux; and (3) attention to power, politics and agency. Together, these foundations signal a coherency to assemblage thinking and suggest an assemblage approach has powerful potential, allowing researchers to see and explain things in ways that many established traditions in policy research do not. By identifying foundations and offering examples of how each might be mobilized, the paper provides the beginnings of a framework for policy assemblage research not previously articulated in a systematic form, thus inviting further discussion about what it means to undertake policy assemblage research.

Keywords: Assemblages. Public policy. Mobility. Power.

Resumen: La teoría sobre agenciamiento explotó en la investigación sobre políticas, especialmente entre los investigadores que trabajan en el área de movilidad y buscan aprovechar el potencial de este enfoque para comprender cómo las políticas se mueven, cambian y se manifiestan en contextos cada vez más transnacionales. La ubicuidad del agenciamiento, sin embargo, no siempre lo hace preciso, siendo el concepto definido de formas variadas y, a veces, carente de fuerza conceptual y poder explicativo. Este artículo busca conceptualizar y defender un enfoque sobre el agenciamiento para análisis de políticas. Al sintetizar los ejes centrales de la literatura existente, identifica tres fundamentos teóricos y conceptuales centrales para un abordaje sobre el "agenciamiento de políticas": (1) relaciones de exterioridad y emergencia; (2) heterogeneidad, relacionalidad y flujo; y (3) atención al poder, política y agencia. Juntos, estos fundamentos señalan una coherencia para la teoría del agenciamiento y sugieren un enfoque con un poderoso potencial, permitiendo que los investigadores vean y expliquen las cosas de maneras que muchas tradiciones establecidas en la investigación de políticas no consiguen. Al identificar los fundamentos y ofrecer ejemplos de cómo cada uno puede ser movilizado, el artículo proporciona el inicio de un marco teórico aún no articulado de forma sistemática para la investigación sobre agenciamiento de políticas, invitando así, a una discusión más profunda sobre lo que significa llevar a cabo este tipo de trabajo.

Palabras clave: Agenciamiento. Políticas públicas. Movilidad. Poder.

\section{Introdução}

A teoria sobre o agenciamento explodiu'. Teórica, conceitual e metodologicamente, pesquisadores em uma ampla variedade de campos estão buscando aproveitar o potencial dessa abordagem para gerar ideias sobre um espectro diversificado de formações sociais. Ao conceituar agenciamentos como construções relacionais, compostas por componentes heterogêneos e emergentes organizados em conjunto para determinados fins estratégicos, em espaços e tempos particulares, os pesquisadores têm se engajado com pensamento do agenciamento para dar sentido a uma série de fenômenos, que vão desde a formação de cidades (McCann \& Ward, 2011), relações internacionais (Acuto \& Curtis, 2014) e vários "agenciamentos globais" (Ong \& Collier, 2005), a formações políticas específicas, como práticas de criação de porcos na União Europeia (Dunn, 2005), práticas de manejo florestal na Indonésia (Li, 2007) e políticas de "indústrias criativas" na Nova Zelândia (Prince, 2010). Pesquisadores ancoram seus estudos em um conjunto de teorias fundamentais que se relacionam. Central tem sido a filosofia de Gilles Deleuze e Félix Guattari,

\footnotetext{
${ }^{1}$ Nota do revisor: em inglês, o termo usado pelo autor é assemblage theory, de modo que assemblage tem tanto função adjetiva quanto substantiva para seu acompanhante "teoria". O termo descende da apropriação e constituição de um campo, no contexto de países de língua inglesa, receptivo a obra de Gilles Deleuze e Félix Guattari, cujo movimento não encontra similaridade na ampla difusão do pensamento dos filósofos no Brasil, incluindo no campo educacional. Trata-se do conceito em francês de agencement, formulado pelos autores em obras como Kafka: por uma literatura menor e o primeiro volume de Mil platôs. Esse conceito foi traduzido em português por agenciamento, o qual optamos por usar nesta tradução em vez da opção mais literal de traduzir assemblage por montagem. Nesse sentido, também optamos por traduzir o termo policy assemblage, usado por Glenn Savage neste texto, por "agenciamento de políticas", em vez de agenciamento político, a fim de ecoar a proposta de uma teoria equipada para pesquisar sobre a co-constituição, mobilidade e volatilidade de determinadas políticas. Entretanto, o termo "agenciamento político" foi mantido em alguns trechos quando não se referia a uma abordagem de pesquisa, mas à dimensão política do agenciamento.
}

Práxis Educativa, Ponta Grossa, v. 17, e2220018, p. 1-21, 2022 Disponível em: <https://revistas2.uepg.br/index.php/praxiseducativa> 
que utilizaram o conceito de agenciamento (agencement em francês) para compreender a composição heterogênea de formações sociais e não sociais complexas. A articulação de agenciamentos sociais de Bruno Latour (2005) no campo da teoria ator-rede também é utilizada regularmente, assim como a teoria "reconstruída" do agenciamento de Manuel DeLanda (2006, 2016), que se baseia em Deleuze e Guattari, mas também se assenta fortemente em ideias da teoria da complexidade.

O interesse ampliado no pensamento sobre o agenciamento gerou um intenso empenho em explorar e esclarecer ainda mais o potencial desta abordagem (Anderson \& MacFarlane, 2011; Baker \& McGuirk, 2017) e também inspirou críticas, desde aqueles que questionaram a coerência e a utilidade do conceito de agenciamento (Brenner, Madden, \& Wachsmuth, 2011) até aqueles que defendem o conceito, mas argumentam que as articulações contemporâneas se desviaram inutilmente dos fundamentos estabelecidos por Deleuze e Guattari (Buchanan, 2015; Nail, 2017). Ao mesmo tempo, agenciamento tem sido conectado a um espectro de conceitos semelhantes, mas distintos, incluindo o conceito foucaultiano de dispositivo (Legg, 2011; Li, 2007), e outros conceitos derivados de pesquisas focadas em redes transnacionais, mobilidades e entendimentos topológicos de espaço e poder (Allen \& Cochrane, 2010; Prince, 2017).

Ao tomar como pano de fundo essa manifestação mais ampla, este artigo tem por objeto de análise um corpo de estudos que procurou aproveitar o conceito de agenciamento para entender os processos políticos contemporâneos: isto é, processos de agenciamento de políticas. Mais especificamente, seu interesse está em sintetizar e construir estudos nos campos da geografia crítica, estudos críticos de política, sociologia e antropologia, que posicionaram o agenciamento como parte do campo emergente da pesquisa sobre mobilidade política. Embora este trabalho seja variado em forma, intenção e foco empírico, ele é unificado por um objetivo e um desafio comum de desenvolver abordagens mais sutis para entender como as políticas se movem, mudam e se manifestam em espaços e tempos particulares, em um contexto de intensos fluxos transnacionais de ideias e práticas políticas (Gulson et al., 2017; McCann \& Ward, 2012; Peck \& Theodore, 2015). $\mathrm{O}$ agenciamento tem sido disposto como uma ferramenta geradora para abordar os limites dos debates e dos conceitos estabelecidos, especialmente aqueles relacionados à transferência, ao empréstimo e à difusão de políticas, mas também foi apresentado como um conceito para corrigir explicações racionais-tecnicistas, institucionalistas e centradas no Estado e nos processos de governança (Clarke, Bainton, Lendvai, \& Stubbs, 2015; McCann \& Ward, 2012; Peck \& Theodore, 2015; Shore, Wright, \& Pero, 2011; Temenos \& McCann, 2013; Ureta, 2015). Em alguns casos, o agenciamento é usado como parte de uma distinção de três elementos naquilo que foi chamado de abordagem política de "agenciamento, mobilidades e mutação" (McCann \& Ward, 2013). Outro trabalho se concentrou em reunir agenciamento com um conceito relacionado ao de "tradução" para capturar os processos pelos quais as políticas passam à medida que viajam e são reagrupadas em novos locais (Clarke et al., 2015). Em outros casos, o interesse por mobilidades e tradução foi submetido a uma lente do agenciamento (Savage \& Lewis, 2018).

Apesar da crescente popularidade do agenciamento na pesquisa de políticas e dos horizontes de esperança que promete oferecer aos pesquisadores de políticas, o conceito permanece definido de várias maneiras e, em alguns casos, carece de precisão conceitual ou metodológica (Baker \& McGuirk, 2017; Savage, 2018). Além disso, como argumenta Allen (2011), há também uma forte tendência de o agenciamento ser usado de forma excessivamente descritiva, levando, na pior das hipóteses, a uma análise que representa "um simples exercício de junção" (p. 156) - ou o que ele chama de "estreita" e "descrição sem fim" (p. 154). Em outras palavras, uma abordagem sobre o agenciamento corre o risco de se tornar uma justificativa para (e processo de) apenas mapear e descrever vários pedaços e fragmentos da política, mas de uma forma que oferece uma "conceituação fraca" (p. 154) e insuficiente em termos de explicar fenômenos de novas maneiras ou avançar em argumentos úteis (Brenner et al., 2011). Pior ainda, à medida que o conceito

Práxis Educativa, Ponta Grossa, v. 17, e2220018, p. 1-21, 2022 Disponível em: <https://revistas2.uepg.br/index.php/praxiseducativa $>$ 
aumenta em popularidade e diversidade de uso, ele corre o risco de emergir como um significante vazio, significando tudo e qualquer coisa ao mesmo tempo (Anderson \& MacFarlane, 2011), e potencialmente de maneiras desvinculadas do trabalho que procurou articular cuidadosamente os pontos fortes e os limites do conceito. Em última instância, portanto, a ubiquidade do agenciamento não o torna necessariamente preciso. Isso não quer dizer que o agenciamento deva ter um significado fixo ou ser ancorado exclusivamente no trabalho de pesquisadores específicos (Allen, 2011; Anderson \& MacFarlane, 2011), mas, se faltar uma "conceitualização pensada" e coerente (Allen, 2011, p. 156), será difícil articular, defender e estender seu uso de forma produtiva na pesquisa sobre políticas.

À luz dessas preocupações bem estabelecidas, este artigo busca conceituar e defender uma abordagem sobre o agenciamento para análise de políticas, demonstrando que o agenciamento tem, de fato, um forte potencial gerador, especialmente para aqueles pesquisadores que trabalham no campo das mobilidades das políticas. A fim de abordar as preocupações sobre a falta de precisão conceitual e poder explicativo, este artigo sintetiza a literatura existente e identifica três fundamentos centrais que são teórica e conceitualmente essenciais para uma abordagem sobre o agenciamento de políticas: (1) relações de exterioridade e emergência; (2) heterogeneidade, relacionalidade e fluxo; e (3) atenção ao poder, política e agência. Juntos, esses fundamentos sinalizam uma coerência para pensar o agenciamento e sugerem que abordá-lo tem um poderoso potencial ao permitir que os pesquisadores vejam e expliquem as coisas de maneiras que muitas tradições estabelecidas na pesquisa de políticas não conseguem. Ao identificar os fundamentos e oferecer exemplos de como cada um pode ser mobilizado, o artigo fornece o início de um arcabouço para a pesquisa do agenciamento de políticas ainda não articulado de forma sistemática, convidando, assim, a uma discussão mais aprofundada sobre o que significa realizar pesquisa sobre agenciamento de políticas. Em certo sentido, portanto, o objetivo é fazer, em termos teóricos e conceituais, o que Baker e McGuirk (2017) tentaram recentemente em termos metodológicos, delineando o que eles veem como elementos centrais de um arcabouço metodológico para a pesquisa do agenciamento. De outra forma, a análise também busca fornecer, mas com mais detalhes, uma articulação das semelhanças que existem em toda a pesquisa sobre agenciamento, de forma a estender o trabalho de Anderson e MacFarlane (2011) com um foco específico na pesquisa sobre políticas (em vez de geografia crítica especificamente). Em última análise, a expectativa é que este artigo responda frutiferamente às preocupações de Allen (2011), mostrando que o agenciamento de fato "nos permite fazer certas coisas e nos permite pensar de certas maneiras que não eram possíveis antes"; e pode, portanto, significar muito mais do que "uma moda passageira ou moda intelectual" (p. 154).

\section{Agenciamento de políticas: três fundamentos centrais}

Embora todas as teorias e todos os conceitos sejam necessariamente incompletos, sejam trabalhos idealmente criativos e em movimento e estejam em direção a um maior poder explicativo, é importante que os estudiosos que trabalham com teorias e conceitos compartilhados busquem alguma medida de compreensão partilhada sobre os fundamentos que definem amplamente sua abordagem. Isso é importante não apenas para compor uma linguagem comum e mais refinada, mas também para impulsionar os estudos por meio do fornecimento de estruturas analíticas que podem ser direcionadas, desafiadas e revisadas. À medida que o uso do agenciamento se expande rapidamente na pesquisa sobre políticas, um campo definido como pesquisa sobre o "agenciamento de políticas" está despontando (Savage, 2018). No entanto, embora exista um "amplo consenso" (Baker \& McGuirk, 2017, p. 428) sobre a utilidade do pensamento sobre agenciamento, não há nenhuma tentativa sistemática de fazer um balanço da "notável diversidade com que o termo passou a ser usado" (Anderson \& MacFarlane, 2011, p. 124). No que segue, este artigo procura

Práxis Educativa, Ponta Grossa, v. 17, e2220018, p. 1-21, 2022 Disponível em: <https://revistas2.uepg.br/index.php/praxiseducativa $>$ 
produzir o início de um arcabouço teórico para a pesquisa sobre agenciamento de políticas, argumentando que os três fundamentos centrais a seguir são essenciais para esta abordagem.

\section{Relações de exterioridade e emergência}

O conceito de agenciamento reflete uma compreensão distinta da relação entre as partes e o todo, que é frequentemente articulada por meio do que tem sido chamado de "relações de exterioridade". Essa visão única da relação entre as partes e o todo reflete os princípios centrais da teoria da complexidade sobre o conceito de "emergência" e se reflete implícita ou explicitamente em quase todas as pesquisas sobre políticas que adotam uma análise do agenciamento. Reconhecer as relações de exterioridade e emergência tem implicações significativas sobre como podemos entender os processos do agenciamento de políticas, bem como sistemas políticos mais amplos e outras formações sociais.

A “teoria reconstruída dos agenciamentos" de DeLanda $(2006,2016)$ baseia-se diretamente no trabalho de Deleuze e Guattari e fornece uma das análises mais detalhadas das relações de exterioridade e implicações associadas para a compreensão da relação entre partes e todos. Embora DeLanda não se concentre na política em um sentido explícito, sua análise de nações, governos, organizações e redes se traduz poderosamente em uma discussão sobre como o conceito de agenciamento pode informar a pesquisa política. Por essa razão, suas ideias foram adotadas por vários estudiosos de políticas que trabalham com uma abordagem sobre o agenciamento. Central para a articulação de agenciamento de DeLanda (2006) é uma crítica ao que ele chama de "a metáfora organísmica" (p. 4). Baseando-se fortemente na teoria da complexidade, DeLanda (2006) argumenta que os cientistas sociais, muitas vezes, tratam as formações sociais como semelhantes a organismos biológicos que têm lógica e ordem internas e, como resultado, enquadram as partes componentes das formações sociais como semelhantes a "órgãos corporais" (p. 8). Tais perspectivas, ele argumenta, produzem uma compreensão distorcida da relação entre partes e o todo; ou, o que ele chama de "os níveis micro e macro da realidade social" (p. 4).

Esse "problema micro-macro", argumenta DeLanda (2006, p. 4), é atormentado por duas formas contrastantes de reducionismo. Primeiro, há uma tendência para o micro-reducionismo, por meio do qual o todo é enquadrado como "um mero agregado" (p. 4) de partes componentes individuais. O problema de entender o todo como simplesmente a soma de suas partes é que obscurecemos as "propriedades emergentes e irredutíveis" (p. 10) do todo, ou seja, propriedades que existem apenas como resultado de interações contingentes que ocorrem entre as partes componentes, isto é, propriedades que seriam diferentes se os componentes fossem organizados de forma diferente. Isso reflete fortemente as teorias de emergência no campo da teoria da complexidade que destacam as propriedades irredutíveis dos sistemas complexos, enfatizando que a natureza dos sistemas só pode ser entendida em referência a como suas partes constituintes se relacionam e geram características emergentes particulares (Geyer \& Rihani, 2010; Urry, 2003). Como escreve DeLanda (2006), as propriedades de um todo "não podem ser reduzidas às de suas partes", porque "são o resultado não de uma agregação das propriedades próprias dos componentes, mas do exercício real de suas capacidades" (p. 11, ênfase no original). Ele acrescenta: "Essas capacidades dependem das propriedades de um componente, mas não podem ser reduzidas a elas, pois envolvem referência às propriedades de outras entidades que interagem" (p. 11). Em suma, em vez de entender uma política como algo coerente ou definível como a soma de seus componentes constitutivos, uma abordagem sobre o agenciamento enfatiza que o mais importante é entender a natureza das interações entre os componentes e as capacidades que esses componentes exibem quando organizados de maneiras diferentes. Isso, por sua vez, chama atenção para a compreensão das relações de poder que tornam alguns agenciamentos possíveis e outros não. Por

Práxis Educativa, Ponta Grossa, v. 17, e2220018, p. 1-21, 2022 Disponível em: <https://revistas2.uepg.br/index.php/praxiseducativa $>$ 
exemplo, a formação de uma política nacional normalmente se baseia no novo agenciamento de um espectro diversificado de componentes potenciais (leis, atores, organizações, tecnologias de governança, processos de prestação de contas etc.) que devem ser aproveitados e organizados em conjunto, em uma forma que encoraje a política a servir às suas funções pretendidas e operar de maneiras específicas. As maneiras particulares em que os componentes são reunidos determinarão as propriedades e os efeitos de qualquer política ou agenda; e se os mesmos componentes fossem dispostos de forma diferente, ou novos componentes fossem introduzidos ou excluídos, então seriam produzidas propriedades e efeitos diferentes. Como Rabinow (2014) argumenta, as maneiras particulares pelas quais os componentes autônomos são reunidos em um agenciamento inevitavelmente tornarão "algumas coisas e eventos possíveis e outros improváveis" (p. 206). Por essa razão, como argumenta Li (2007), uma abordagem sobre o agenciamento convida a perguntar como certas políticas são "feitas para serem coerentes", enquanto, ao mesmo tempo, os potenciais para fazer políticas de outra forma são desvelados. Como tal, essa abordagem abre janelas para imaginar a política de forma diferente (e com objetivos políticos potencialmente normativos em mente) em termos de considerar como novos agenciamentos podem ser forjados com impactos e possibilidades diferentes e potencialmente mais positivos, isto é, novas e diferentes formas de emergência (Tampio, 2009).

A segunda tendência que DeLanda critica é o macro-reducionismo, que, ao contrário do microreducionismo, enquadra os componentes individuais de um agenciamento como sendo "meros produtos" (DeLanda, 2006, p. 4) do todo. Aqui, cria-se o problema inverso, pelo qual partes individuais de uma formação social são vistas como determinadas, principalmente pela natureza da própria formação. Esse é um problema comum na ciência política e na sociologia, no qual os pesquisadores entendem componentes específicos de um sistema político ou de uma política como sendo principalmente o resultado desse sistema ou política. Por exemplo, um pesquisador pode enquadrar um componente-chave de um sistema nacional (uma lei, política, organização ou ator em particular) como sendo principalmente um produto desse sistema e, portanto, como tendo certas características ou operando de certas maneiras com base em pontos de vista ou suposições sobre a natureza mais ampla desse sistema. Embora isso possa parecer lógico a princípio, na verdade é profundamente problemático, especialmente em contextos contemporâneos em que as formações de políticas são cada vez mais orientadas por mobilidades políticas transnacionais que atravessam territórios políticos de novas maneiras. Como Savage e Lewis (2018) argumentam em relação às reformas escolares nacionais na Austrália, embora certas políticas possam ser ostensivamente nacionais e australianas em termos de seu escopo legislativo e territorialização como tecnologias implementáveis de governança, é equivocado "explicar" políticas como simplesmente "produtos" da política escolar australiana. De fato, ao adotar uma abordagem sobre o agenciamento para traçar o desenvolvimento de políticas, eles demonstram como a criação de padrões nacionais de ensino na Austrália foi o resultado de um número diversificado de componentes que foram fortemente orientados por fluxos transnacionais de atores políticos, ideias e práticas, que se manifestaram de maneiras específicas no lugar. Em outras palavras, ideias políticas, práticas e formas de influência podem ser fortemente orientadas por fluxos transnacionais, mas as condições de possibilidade para tais políticas dependem em grande parte das condições locais de possibilidade. Como resultado, tais políticas, e os componentes centrais que as tornam reais, podem parcialmente, mas não totalmente, ser entendidas como artefatos de contextos políticos e políticos nacionais.

A principal implicação de rejeitar tanto o macro quanto o micro reducionismo é que, em vez de entender os conjuntos de políticas como constituídos por relações de interioridade, em que as partes componentes têm uma relação necessária ou essencial umas com as outras, ou "formam um todo sem costura" (DeLanda, 2006, p. 4), os agenciamentos se caracterizam por relações de exterioridade, nas quais "uma parte componente de um agenciamento pode ser destacada dele e encaixada em um agenciamento diferente no qual suas interações são diferentes” (p. 10). Como tal,

Práxis Educativa, Ponta Grossa, v. 17, e2220018, p. 1-21, 2022 Disponível em: <https://revistas2.uepg.br/index.php/praxiseducativa $>$ 
em vez de as relações entre as partes componentes serem entendidas como logicamente necessárias para tornar o todo o que é, as relações em um conjunto são vistas como "apenas contingentemente obrigatórias" (p. 11, ênfase no original). Novamente, isso reflete fortemente o anti-reducionismo e o compromisso com o holismo na teoria da complexidade (Urry, 2003). DeLanda (2016) aprofundou essa ideia em trabalhos recentes, argumentando:

Ao contrário de totalidades em que 'ser parte do todo' é uma característica definidora das partes, isto é, todos em que as partes não podem subsistir independentemente das relações que mantêm umas com as outras (relações de interioridade), precisamos conceber totalidades emergentes em que as partes mantenham sua autonomia, de modo que possam ser desvinculadas de um todo e conectadas a outro, entrando em novas interações. (p. 10)

Isso também é enfatizado por Rabinow (2014), que argumenta que um agenciamento "não é uma coisa pré-existente do mundo com propriedades pré-dadas", mas, em vez disso, "reúne entidades do mundo em uma proximidade na qual estabelecem relações entre e dentre si, permanecendo externos um ao outro e, assim, retendo suas propriedades originais" (p. 206).

Adotar uma posição anti-reducionista que entende os agenciamentos como definidos por relações de exterioridade e como geradores de propriedades emergentes tem um grande número de implicações para os estudiosos da política contemporânea. Além das implicações já levantadas, ao resistir tanto ao macro quanto ao micro-reducionismo, a teoria do agenciamento apresenta um desafio fundamental à distinção tradicional estrutura/agência, que tem várias implicações associadas para fazer pesquisa política. As descrições que privilegiam a agência sobre a estrutura tendem ao micro-reducionismo, enquanto as descrições que privilegiam a estrutura sobre a agência favorecem o macro-reducionismo. Ao rejeitar ambos, somos forçados não apenas a questionar a relevância do binário estrutura/agência, mas também a repensar uma série de fenômenos políticos, por exemplo o modo como os indivíduos são moldados por políticas ou sociedades, como entendemos o poder de atores políticos e organizações, como as formações de nível micro podem contribuir para tendências mais amplas de nível meso ou macro e muito mais. Como Urry (2003) escreve em relação a dinâmicas semelhantes na teoria da complexidade, tais abordagens para entender as formações sociais "subvertem essa mesma distinção entre agência e estrutura" (p. 111). Isso também tem implicações importantes na forma como entendemos os impactos e os resultados das políticas. Por exemplo, uma abordagem anti-reducionista significa que não podemos supor que exista qualquer relação linear ou direta entre as políticas e os impactos que surgem nos contextos em que tais políticas são postas em prática. Dito de outra forma, uma política pode procurar gerar certos efeitos, mas a extensão em que o faz ou não raramente (ou nunca) pode ser atribuída exclusivamente à própria política. Além disso, as políticas podem (e muitas vezes produzem) impactos que não podem ser previstos com antecedência (Ureta, 2015) ou que, no mínimo, só podem ser entendidos examinando como a própria política interage com outras partes componentes para produzir certas características emergentes. Chamar atenção para essas complexidades e para os mundos sociais que delineiam os processos de atuação das políticas complica enormemente os pressupostos centrais que continuam a sustentar a grande maioria das pesquisas conduzidas nos campos de implementação e de avaliação de políticas. De fato, vemos que essas pesquisas sofrem profundamente com modelos de avaliação que se baseiam fundamentalmente em formas de reducionismo (muitas vezes por meio da exclusão da vida social da política e/ou das complexidades dos componentes nos quais uma intervenção política intervém) para isolar a política a fim de compreender impactos e efeitos (Geyer \& Rihani, 2010).

Complicar a inter-relação entre política e impacto tem implicações significativas quando se vê através do prisma dos debates contemporâneos sobre políticas baseadas em evidências, empréstimos de políticas e o fascínio entre formuladores de políticas e pesquisadores em identificar

Práxis Educativa, Ponta Grossa, v. 17, e2220018, p. 1-21, 2022 Disponível em: <https://revistas2.uepg.br/index.php/praxiseducativa $>$ 
abordagens sobre "o que funciona" para problemas políticos (Lewis, 2017; Parkhurst, 2017; Peck \& Theodore, 2015). Por exemplo, entender as políticas como conjuntos contingentes, definidos por relações de exterioridade e tornados específicos do local em termos de forma e impacto, desafia fundamentalmente as suposições de que exemplos de políticas de "melhores práticas" podem simplesmente ser emprestados de um contexto político e implementados em outro com os mesmos ou semelhantes impactos. Em outras palavras, só porque uma política de prevenção ao crime na Finlândia pode conter certos componentes que são organizados de maneiras particulares e operam com impactos positivos naquele contexto, isso não significa que esses componentes terão os mesmos efeitos positivos em Cingapura ou nos Estados Unidos. Isso ocorre porque, quando tais componentes de políticas são montados em um novo contexto, os próprios componentes serão contornados por vários fatores dependentes do contexto, isto é, condições específicas de possibilidade, que tornarão os componentes específicos do local e resultarão no estabelecimento e na manutenção de novas relações entre esses componentes e os componentes existentes no novo ambiente. Vemos, portanto, que as políticas sofrem formas de mutação, tradução e (re)agenciamento à medida que transitam entre diferentes contextos políticos (McCann \& Ward, 2013). Esse é um argumento definidor no campo emergente das mobilidades políticas e uma das razões pelas quais a abordagem sobre o agenciamento ganhou tanta força nesse campo, especialmente na última década. Em vez de perguntar "o que funciona", portanto, talvez os melhores formuladores de políticas possam esperar perguntar: o que pode funcionar aqui se a política for adotada e adaptada aos contextos locais de uma maneira que permaneça ciente dos múltiplos componentes e fatores específicos do contexto que precisam ser considerados e estrategicamente organizados para tornar a política viável? Essa forma mais modesta de questionamento reconhece que "muito não pode ser engarrafado para exportação" (Peck \& Theodore, 2015, p. xvii). Também lembra que "enquanto a imaginação da formulação de políticas pode estar se globalizando e enquanto os circuitos transnacionais de especialização e prática estão proliferando, a realidade obstinada é que fazer as políticas funcionarem muitas vezes continua sendo um assunto prático, confuso e muito "local"' (p. xvii). É claro que a probabilidade de tais questionamentos diferentes e a consideração do contexto ganharem força generalizada no mundo da formulação de políticas é baixa, pois o próprio fascínio da abordagem "o que funciona" é sua promessa de soluções viáveis, não a problematização de soluções e a introdução de incerteza.

\section{Heterogeneidade, relacionalidade e fluxo}

Agenciamentos são heterogêneos, compostos por uma multiplicidade de partes componentes que foram organizadas juntas para fins estratégicos particulares. Dado os compromissos já mencionados com as relações de exterioridade, o anti-reducionismo e a rejeição de "todos coerentes", as partes heterogêneas que constituem um agenciamento também são entendidas como tendo uma relação contingente e não necessária, reunidas em configurações relacionais particulares que têm características mutáveis em vez de formas fixas. Isso significa que uma abordagem sobre o o agenciamento enfatiza a natureza sempre em movimento e evolução das formações sociais. As relações complexas entre heterogeneidade, relacionalidade e fluxo - e como esses recursos podem informar essa abordagem para uma análise de políticas - exigem uma aproximação cuidadosa.

Para começar, é crucial notar que, apesar de serem heterogêneos e sintéticos na forma, os agenciamentos não são simplesmente uma leatória de coisas. Os agenciamentos não são semelhantes a um conglemarado aletatório de pedaços e peças que simplesmente existem juntos. Agenciamentos não são tudo e nada. Em vez disso, como argumenta Ureta (2015), os agenciamentos são o resultado de elementos heterogêneos que são reunidos em relações estratégicas particulares e com impactos desejados próprios. Baseando-se na noção de Law (1994) de "modos

Práxis Educativa, Ponta Grossa, v. 17, e2220018, p. 1-21, 2022 Disponível em: <https://revistas2.uepg.br/index.php/praxiseducativa> 
de ordenação", a conceituação do agenciamento de políticas de Ureta presta muita atenção aos processos dinâmicos pelos quais elementos heterogêneos se unem para transformar agenciamentos existentes em algo novo. Os modos de ordenação, argumenta Ureta (2015), "são heterogêneos e variáveis, mas sempre incluem a busca de efeitos estratégicos, o objetivo de transformar uma situação existente de uma certa maneira predeterminada por meio do estabelecimento de conjuntos particulares de relações entre entidades novas e existentes" (p. 12). Em vez de ser um agrupamento, um agenciamento de políticas pode ser entendido como um agenciamento de componentes de maneiras particulares com o objetivo de governar a conduta - ver Buchanan (2017) e Nail (2017), para uma discussão sobre o termo "agenciamento" e como ele se relaciona com o uso de agenciamento na obra de Deleuze e Guattari. Enquanto, por exemplo, dentro de uma nação existem vários componentes de política e governança, a mera existência desses componentes não faz um conjunto. Em vez disso, um agenciamento refere-se aos casos em que os componentes foram estrategicamente dispostos com o objetivo de formar um dispositivo para governar. Essa conceituação do agenciamento reflete o argumento de Li (2007) de que a composição de um agenciamento é o resultado de "trabalho árduo necessário para reunir elementos heterogêneos, criar conexões entre eles e sustentar essas conexões diante da tensão" (p. 264). Mais uma vez, porém, enquanto tais processos de agenciamento envolvem a composição de vários alinhamentos entre partes heterogêneas, tais alinhamentos não significam que o conjunto tenha uma essência coerente ou racionalidade singular. Em vez disso, uma abordagem sobre o agenciamento chama atenção para as maneiras pelas quais as formações heterogêneas se mantêm juntas, "sem deixar de ser heterogêneas" (Allen, 2011, p. 154). Formas de coerência são assim estabelecidas a partir da multiplicidade. Dito de outra forma, um agenciamento de políticas não tem essência definível além das relações estabelecidas entre seus componentes. Isso não significa que o agenciamento não tenha coerência, mas significa que falta uma essência. Essa distinção entre coerência e essência é fundamental para entender como um agenciamento de políticas pode operar com impactos estratégicos e observáveis, mas sem uma lógica orientadora singular, o que, por sua vez, tem grandes implicações em como entendemos o poder (veja a próxima seção). Como Deleuze (2002) argumentou, "a única unidade do agenciamento é a de co-funcionamento: é uma simbiose. (...). O que é importante não são nunca as filiações, mas as alianças e as ligas" (p. 52). O foco nas ligas, cofuncionamento e formas sintéticas reforça ainda mais a distinção entre as relações de interioridade e exterioridade. Por exemplo, ao contrário de uma bicicleta, para a qual as partes componentes (corrente, engrenagens, pedais etc.) cumprem uma função estratégica de maneiras que são logicamente necessárias para tornar o todo o que é, as relações em um agenciamento de políticas também cumprem funções estratégicas, mas são compostas de relações contingentemente obrigatórias que estão sempre evoluindo na forma.

Reconhecer a mutabilidade dos agenciamentos requer atenção analítica próxima aos processos de fluxo. No nível ontológico, o pensamento de agenciamento reflete a crença de que a kinesis (i.e., o movimento de formas e ritmos variados) é fundamental para a natureza da realidade social. Nail (2015) descreve o conceito de kinesis em relação ao que ele denomina uma ontologia do movimento, que, em suma, significa entender a sociedade e suas diversas formas como "sempre em movimento" (p. 4). Ele acrescenta: "As sociedades não são lugares estáticos com características e pessoas fixas. As sociedades são processos dinâmicos engajados em dirigir e circular continuamente a vida social. Em uma filosofia orientada para o movimento não há estagnação social, apenas regimes de circulação social" (p. 4). Devemos, portanto, "compreender a própria sociedade segundo o movimento" (p. 4, ênfase no original). Quando relacionado ao agenciamento e à análise de políticas, isso requer uma abordagem analítica que não seja apenas sensível a como várias partes componentes são reunidas em tecnologias de governança coerentes e estrategicamente orientadas, isto é, agenciadas, mas também atenta às muitas maneiras pelas quais as políticas estão sujeitas a formas de perturbação e mudança (desagenciamento ou reagenciamento). De fato, vários estudiosos de políticas chamaram atenção para esses processos de re/des/agenciamento (Savage \& Lewis, 2018;

Práxis Educativa, Ponta Grossa, v. 17, e2220018, p. 1-21, 2022 Disponível em: < https://revistas2.uepg.br/index.php/praxiseducativa $>$ 
Youdell \& McGimpsey, 2015). Ao fazê-lo, chamaram atenção para os processos complexos por meio dos quais as políticas surgem, mas também são (muitas vezes simultaneamente) desmanteladas e reagenciadas em novas formas. Savage e Lewis (2018), por exemplo, usam os termos "agenciar", "desagenciar" e "reagenciar" de maneiras que conversam diretamente com os conceitos de territorialização, desterritorialização e reterritorialização de Deleuze e Guattari. Como eles observam, Deleuze e Guattari usaram esses termos para descrever como os agenciamentos se reúnem (territorialização), se desfazem (desterritorialização), ou para entender casos em que agenciamentos existentes são rompidos e reagrupados (reterritorialização) (Deleuze \& Guattari, 1987). Os agenciamentos sempre incluem, portanto, um jogo complexo entre tendências territorializantes, desterritorializantes e reterritorializantes, com alguns componentes trabalhando para estabilizar o agenciamento e outros para transformá-lo (Ureta, 2015). Como McCann e Ward (2012) escreveram, "um agenciamento está sempre em processo de união (...) assim como está sempre potencialmente se separando" (p. 328, ênfase no original).

Novamente, quando entendido contra o pano de fundo de uma ontologia do movimento, isso significa que uma abordagem sobre o agenciamento rejeita a proposição de que políticas ou sistemas políticos (ou qualquer outra formação social) possam ser totalmente estáticos na forma. Enfatizar o fluxo perpétuo e a simultaneidade de re/des/agenciar, no entanto, não significa que as políticas nunca sejam formadas - leis, padrões, sistemas de responsabilização etc. obviamente "existem" - ou que as políticas não podem manter períodos de estabilidade e fixidez temporária. Em vez disso, significa que: (1) a partir do momento em que qualquer política é formada, ela já está sujeita a formas de perturbação, desafio e múltiplas interpretações; (2) quando performada, uma política muitas vezes assume formas muito variadas, com impactos parcialmente previsíveis e imprevisíveis; e (3) todas as políticas eventualmente serão desfeitas, isto é, desaparecerão ou mudarão de forma. As políticas nunca existem, portanto, como uma coisa "completa", desde tempos imemoráveis, mas estão sempre sujeitas a interpretações múltiplas e em evolução, promulgações e (muitas vezes) reformas ou descontinuações. Para tomar emprestado de Deleuze (1992), vemos que "o atual não é o que somos, mas sim o que somos em processo de vir a ser" (p. 164). Considerações temporais são, desse modo, cruciais. Como Savage e Lewis (2018) argumentam, enquanto algumas políticas "podem dar uma ilusão de estabilidade, uma visão mais ampla acaba revelando movimento constante e novos começos" (p. 124, ênfase no original). Mesmo quando uma política parece abrangente em suas formas e efeitos, uma visão histórica mais ampla sempre revela que a política é um artefato da época, que sempre poderia e iria mudar. Vários outros estudiosos de políticas enfatizaram esse fluxo temporal ao adotar uma abordagem sobre o agenciamento. Ureta (2015), por exemplo, argumenta que as políticas não são “sólidas ou estáveis", mas são "concatenações temporárias de entidades heterogêneas, sempre à beira de se tornar algo completamente diferente" (p. 12). Ou, como sugere Tampio (2009, p. 394), um agenciamento "se transforma perpetuamente, como uma nuvem que se junta e perde moléculas de água". As políticas estão, nesse sentido, "sempre em construção, sempre em movimento" (Kingfisher, 2016, p. 14). De fato, a manutenção de uma política de forma coerente e por um período prolongado é muitas vezes a exceção que confirma a regra, dadas as consistentes pressões e contestações às quais as políticas estão inevitavelmente sujeitas (Shore et al., 2011), especialmente em contextos contemporâneos em que a febre da reforma é abundante.

Os fundamentos teóricos estabelecidos até aqui, especialmente no que diz respeito às relações de exterioridade, heterogeneidade e fluxo, encaminham para outro fundamento central da teoria sobre o agenciamento: o compromisso de compreender as formas de relacionalidade. De fato, centralmente conectada a (e parte de) uma ontologia do movimento está uma ontologia relacional: que, no contexto da pesquisa de políticas, significa ver as relações estabelecidas entre os componentes das políticas como tão (se não mais) fundamentais para entender as políticas como os próprios componentes. No mínimo, uma abordagem sobre o agenciamento requer um

Práxis Educativa, Ponta Grossa, v. 17, e2220018, p. 1-21, 2022 Disponível em: <https://revistas2.uepg.br/index.php/praxiseducativa $>$ 
compromisso com alguma forma de pensamento relacional e abordagens analíticas e metodológicas que deem primazia ao entendimento das relações entre os componentes como parte central do trabalho de análise de políticas. Uma abordagem de análise de políticas que afirma adotar o agenciamento, mas que não reflete o pensamento relacional ou abordagens analíticas associadas, dificilmente pode ser entendida como uma abordagem sobre o agenciamento, pois tal abordagem seria desconfortavelmente contra (ou seria totalmente incompatível com) princípios fundamentais da teoria do agenciamento. Como argumenta Bueger (2014), citando Hayden (1995), é essencial para uma abordagem sobre o agenciamento "uma compreensão relacional da realidade" (p. 62), que entenda que "as relações não são fixas e estáveis", mas "são emergentes e performadas" (p. 62). As relações, ele argumenta, "são feitas e refeitas nas práticas", o que significa que o que se exige dos pesquisadores é "um estudo do trabalho prático necessário para gerar relações entre os elementos de um agenciamento" (p. 62). Ong (2014) faz um argumento semelhante, enfatizando os benefícios do conceito de agenciamento em termos de evitar formas de abstração e de reificação em favor de focar nas práticas materiais reais, coisas e relações por meio das quais as formações sociais passam a existir. Uma abordagem sobre o agenciamento para análise de políticas, portanto, "dirige nossa atenção para longe de abstrações teóricas e tipos ideais, que são abundantes na ciência política e estudos de políticas públicas, para orientações mais materialistas, relacionais e de baixo para cima, que buscam entender o material tangível das políticas" (Savage, 2018, p. 310, ênfase no original).

A atenção às formas de relacionalidade é uma razão central pela qual as abordagens do agenciamento ganharam tanta força no campo das mobilidades políticas, especialmente entre geógrafos críticos e sociólogos que trabalham com uma lente topológica (Allen, 2011; Allen \& Cochrane, 2010; Amin, 2002; Hartong, 2018; Lewis \& Lingard, 2015; Prince, 2017). Investigações topológicas buscam romper e reinterpretar narrativas dominantes sobre escala, relações localglobal, exercício de poder e outras dimensões centrais para teorizar as novas espacialidades da globalização. Ao rejeitar a noção euclidiana de espaço como um conjunto de "coordenadas fixas" a priori sobre as quais se desenrolam as relações políticas, de poder e de relações de poder, esses trabalhos topológicos enfatizam a importância das relações estabelecidas através do espaço, ou seja, a criação de espaços relacionais que reúnem o próximo e o distante em novos agenciamentos que não podem ser entendidos em termos de noções fixas de escala territorial (Allen \& Cochrane, 2010). Como Prince (2017) argumenta, uma abordagem topológica "enfatiza a relacionalidade em vez da proximidade", o que significa que "elementos podem ser topologicamente próximos, mesmo que sejam topograficamente distantes" (p. 337-338). Os agenciamentos topológicos são assim constituídos pela "sobreposição de relações próximas e distantes e conexões organizacionais que não são redutíveis a espaços escalares" (Amin, 2002, p. 386); ou, como Thompson e Cook (2015) colocam "o caráter de uma topologia é dado pelas qualidades das conexões que ligam seus elementos e não sua posição no espaço-tempo externo abstrato" (p. 734). Novas relações topológicas, que, segundo Lury, Parisi e Terranova (2012), definem a cultura contemporânea e a globalização, estão servindo poderosamente para refazer as condições de possibilidade de política, poder e governança. Allen e Cochrane (2010) descrevem isso em termos de novas "topologias de poder", que Lewis e Lingard (2015) argumentam serem centrais para o agenciamento de "novas geografias de poder e possibilidades de ação" (p. 624).

Quando usados juntos, agenciamento e topologia são conceitos altamente potentes para fazer pesquisa de mobilidade política (Prince, 2017). Por esse motivo, ambos os conceitos foram aproveitados em pesquisas recentes sobre políticas educacionais, que se concentraram no papel da Organização para Cooperação e Desenvolvimento Econômico (OCDE) na geração de um novo espaço global de medição e governança educacional (Hartong, 2018; Lewis \& Lingard, 2015; Lingard, Sellar, \& Savage, 2014; Savage \& Lewis, 2018). Por meio de um vasto espectro de novas métricas, avaliações padronizadas, tabelas de classificação e repositórios de evidências que afirmam

Práxis Educativa, Ponta Grossa, v. 17, e2220018, p. 1-21, 2022 Disponível em: <https://revistas2.uepg.br/index.php/praxiseducativa> 
oferecer evidências sobre "o que funciona" para melhorar os sistemas educacionais globalmente, a OCDE trouxe sistemas políticos geograficamente distantes e diversos para um novo campo transnacional de comensurabilidade, criando assim uma nova proximidade entre os sistemas educacionais próximos e distantes de maneiras que estão tendo implicações significativas sobre como os sistemas educacionais nacionais e subnacionais são governados e como as definições políticas centrais são compreendidas e debatidas, incluindo conceitos orientadores como desempenho do estudante, equidade, qualidade e a relação entre educação e crescimento econômico. Como resultado, podemos agora "falar de local, locais e locais não local" (Lingard et al., 2014, p. 721) em respeito às relações topológicas estabelecidas por meio de medidas comparativas. A OCDE, portanto, serve como um exemplo do argumento de Prince (2017) de que a "tecnocracia" - ou seja, "os especialistas técnicos que produzem conhecimento ostensivamente neutro e objetivo de objetos como a economia na forma de medidas universais de desempenho econômico" (p. 338) - é uma força cada vez mais poderosa em trazer nações para novos conjuntos topológicos, "muitas vezes na forma de uma escala com o 'melhor' no topo e o 'pior' no fundo" (p. 339). Hierarquizar nações dessa maneira permite novas formas de marco global, aumenta o fascínio em torno da formulação de políticas baseadas em evidências e da abordagem sobre "o que funciona”, e possibilita novas redes transnacionais de políticas à medida que os formuladores de políticas buscam emprestar e aprender com as nações "mais em cima" da escala. Os agenciamentos topológicos estão, assim, facilitando a produção de novas imaginações globais e, como resultado, novos modos de governamentalidade (Ruppert, 2012). Mais uma vez, voltando às relações de exterioridade, ao procurar compreender os agenciamentos topológicos, o que mais importa é procurar compreender a natureza e a estrutura das conexões entre as partes componentes. Em outras palavras, é preciso prestar atenção em como as conexões são feitas, como são essas conexões, o que está conectado com o que e o que essas conexões fazem, isto é, aquilo que possibilitam ou não. Como tal, como um componente de um agenciamento é posicionado em relação a outras partes componentes do agenciamento (e qual é seu papel/potencialidade) torna-se potencialmente mais importante do que "onde" ele está localizado em um sentido topográfico. Fazer esse trabalho requer atenção a questões de poder, política e agência, para as quais o artigo agora se volta.

\section{Atenção ao poder, política e agência}

Concentrar-se no agenciamento de políticas é examinar como vários componentes heterogêneos são organizados para criar formas governáveis. Ao aproveitar estrategicamente as capacidades relacionais de várias partes componentes, os agenciamentos representam uma reunião de imaginações políticas, racionalidades, tecnologias, infraestruturas e agentes para direcionar indivíduos e grupos em direções particulares. No entanto, dada a forma heterogênea e emergente dos agenciamentos, e as complexidades de entender e analisar as relações de exterioridade, a teoria sobre o agenciamento oferece formas altamente complexas, mas potencialmente muito produtivas de entender o poder, a política e a agência; e as formas dependentes do contexto em que essas forças produzem e contribuem para a formulação de políticas.

Com raízes na teoria deleuziana, que estava em estreita conversa com a teoria foucaultiana (Legg, 2011; Tampio, 2009), o agenciamento apresenta uma visão do poder como imanente, capilar e relacional por natureza. O poder não é visto como existindo em "algum lugar" em particular, isto é, em um lugar fixo, mas está em toda parte, sempre fluindo através das coisas, ainda que de maneira disjuntiva e desigual. Em contextos contemporâneos de mobilidade intensificada, a política é muitas vezes possibilitada pelo estabelecimento de novos canais e relações topológicas por meio das quais o poder pode fluir e realizar seu potencial, tanto dentro como entre territórios políticos. Uma implicação central disso é que o poder deve ser entendido não apenas como topológico, mas também como de natureza descentralizada e policêntrica. Em outras palavras, o poder se estende

Práxis Educativa, Ponta Grossa, v. 17, e2220018, p. 1-21, 2022 Disponível em: <https://revistas2.uepg.br/index.php/praxiseducativa $>$ 
através do espaço de novas maneiras e também carece de um centro dominante ou sistema nervoso singular a partir do qual possa estender suas forças. O poder tem, assim, múltiplos nós e centros por intermédio dos quais suas forças se aglutinam, se interconectam e são transformadas e redirecionadas. Como Allen (2009) argumenta, quando pensamos em termos de agenciamentos, redes e relações topológicas, vemos que o poder "não é tanto exercido sobre o espaço ou transmitido através dele", mas é "composto relacionalmente através das interações dos diferentes atores envolvidos" (p. 207).

Isso significa que precisamos pensar de maneiras distintas sobre de onde vem o poder e como ele é colocado em ação para conduzir a conduta dos indivíduos (Foucault, 2007; Miller \& Rose, 2008). Por exemplo, se o poder é uma força imanente, fluindo de maneira disjuntiva por meio de redes policêntricas, então ele também precisa ser visto como plural e volátil: isto é, não como uma coisa sólida ou estável, mas como um arranjo sempre temporário e contingente de forças que podem se fragmentar em diferentes direções, ter diferentes impactos em diferentes contextos e podem ser direcionadas para fins particulares, mas nunca podem ser totalmente contidas. Além disso, longe de ser unidirecional ou de fluxo suave, o poder se torna possível por meio de contestação e resistência contínuas. Como argumenta Li (2005), a política (e as relações de poder que a sustentam) são "o resultado da agência e da luta, e não de um plano mestre", acrescentando que a política não é algo "emergindo totalmente formado de uma única fonte", mas sim é um "conjunto de objetivos, conhecimentos, técnicas e práticas de diversas proveniências" (p. 386). Além disso, a política está "sempre sujeita à contestação e à reformulação por uma série de pressões e forças que não pode conter" (p. 386). Novamente, isso ocorre porque o poder está em toda parte em um agenciamento, o que, se seguirmos o exemplo de Michel Foucault, significa que a resistência também está sempre presente. Como Foucault (1980) argumentou, "onde há poder, há resistência" e, como resultado, "a resistência nunca é uma posição de exterioridade em relação ao poder" (p. 95). Isso não significa que todos os atores e todas as organizações tenham capacidades iguais para exercer agência ou impacto sobre a mudança - o poder não é "distribuído igualmente" (Anderson \& MacFarlane, 2011, p. 125) -, mas significa que o potencial de resistência está sempre presente. A resistência, portanto, não é algo que responde ao poder "de fora", mas está sempre embutida e tecida nas relações de poder. Como Li (2005) sugere, não há "espaços primitivos fora do poder" ou "lugares puros de resistência" fora das relações de poder (p. 385). Mais uma vez, essa visão de poder reflete fortes conexões com a teoria da complexidade, onde os sistemas são retratados como carentes de um único centro governante, definido por relações de exterioridade, possibilitadas por relações de poder que fluem através de redes de maneiras não lineares, e sempre sujeitas a resistência e formas de re/decomposição (Urry, 2003).

Com base na discussão de macro e micro-reducionismo acima, uma visão de conjunto de poder não apenas tem implicações de amplo alcance para a forma como entendemos e pesquisamos o desenvolvimento, a promulgação e o impacto de políticas, mas também tem implicações importantes para a forma como entendemos conceitos estabelecidos, como "o Estado", "a nação" e, de fato, o hífen entre o Estado-nação. Mais uma vez, isso ocorre porque um compromisso de entender os agenciamentos como compostos de partes heterogêneas, reunidas em relações de exterioridade, significa que as várias partes componentes que formam um Estado-nação (organizações, partidos políticos, atores, territórios etc.) são entendidas como apenas parte (mas não o todo) do processo de agenciamento de políticas, e apenas parte (mas não tudo) do que cria as condições de possibilidade para a emergência de políticas em primeiro lugar. De fato, como Tampio (2009) argumenta, o pensamento do agenciamento rompe radicalmente muitas afirmações dominantes sobre o poder e o Estado, afirmando que tanto Foucault quanto Deleuze rejeitam a noção comum de que o poder está principalmente "localizado na máquina do Estado" (Tampio, 2009, p. 390). Não podemos mais assumir que o Estado é o detentor primário do poder, a partir do qual a força é estendida de forma linear ou de cima para baixo, ou mesmo que o poder pode ser

Práxis Educativa, Ponta Grossa, v. 17, e2220018, p. 1-21, 2022 Disponível em: <https://revistas2.uepg.br/index.php/praxiseducativa $>$ 
estendido suavemente pelos espaços de governança. Em vez disso, o Estado é semelhante a um jogador em um jogo dinâmico de poder, com poder fluindo para dentro e para fora do Estado, e através dos territórios políticos, de maneiras complexas e não lineares. Como argumenta Li (2005), não existe um Estado "lá em cima" ou "Estado que tudo vê operando como um repositório préformado de poder espalhado progressivamente e sem problemas por todo o território nacional" (p. 384). Isso não quer dizer que o Estado não tem capacidade de exercer o poder (como tal afirmação seria claramente absurda), mas sim que o Estado não "possui" ou "detém" o poder de forma absoluta, nem tem poder absoluto para estender seu alcance pelo espaço. Em vez de ser um proprietário exclusivo do poder, o Estado pode ser visto como uma força primária na direção do poder: aproveitando-o, canalizando-o e experimentando-o na esperança de guiar a conduta dos indivíduos dentro e às vezes além dos territórios sobre os quais reivindica o controle.

Isso claramente tem implicações em como as formas de resistência são entendidas em relação ao Estado. Em vez de ver a resistência como algo que atua principalmente sobre ou contra o Estado, com o Estado visto como o detentor de poderes que podem de alguma forma ser conquistados ou transferidos para agentes resistivos bem-sucedidos (Tampio, 2009), uma abordagem sobre o agenciamento convida a ver o poder e a resistência como não apenas intimamente conectados, mas como existindo simultaneamente dentro e fora do conjunto de componentes que agem em nome do governo. Como argumenta Li (2005), formas poderosas de resistência muitas vezes residem em agenciamentos políticos como as burocracias: isto é, entre atores e indivíduos engajados com o trabalho central do Estado. O mesmo vale para a produção de políticas, pois, enquanto a máquina do Estado pode estar em uma posição única para agenciar políticas, agindo com autoridade ao fazê-lo, as políticas são formadas por meio de interações com componentes localizados dentro e fora do Estado, e com potencial para compor e resistir certos desenhos de políticas distribuídos por todos os componentes envolvidos no processo de políticas. Dito de outra forma, o Estado não simplesmente faz políticas que podem então ser objeto de resistência por aqueles de fora do Estado, mas, em vez disso, o poder/a resistência está embutido/a em todo o processo de produção e promulgação de políticas. Mais uma vez, portanto, vemos que as políticas não apenas carecem de uma essência ou de uma lógica orientadora singular, mas o mesmo vale para as relações de poder que determinam a natureza de sua produção.

Essa linha de pensamento do agenciamento não se encaixa bem com o uso de categorias reificadas, não apenas no que diz respeito ao Estado-nação, mas também a outros termos como "O mercado", "classe" e outros. De fato, é difícil para os teóricos pensar com agenciamento e, ao mesmo tempo, assumir a existência de tais formas reificadas. Embora essas categorias possam servir a propósitos heurísticos úteis, elas acabam por não captar a complexidade das próprias relações que procuram representar. Sassen (2014), por exemplo, vê o desafio que o agenciamento representa para a reificação como uma de suas armas mais potentes. Em relação ao Estado-nação, ela argumenta que o agenciamento ajuda a "tornar visível como o território não pode ser reduzido nem ao território nacional nem ao território estadual", e também permite "ampliar a categoria de 'território' a uma medida de autonomia conceitual do Estado-nação” (p. 22). Como argumenta Sassen (2014), isso não significa que joguemos categorias estabelecidas "fora da janela", mas, em vez disso, permita "desestabilizá-las ativamente" (p. 18). Mais uma vez, isso demonstra fortes ligações com o trabalho de Foucault, que também defendeu uma abordagem metodológica que não se concentrou em "universais" pré-dados, mas começou a partir de uma posição de examinar como essas categorias são montadas por meio de "práticas concretas" (Foucault, 2008, p. 3). Dito de outra forma, em vez de assumir desde o início que nações ou Estados (ou mesmo políticas nacionais) são coisas pré-existentes a serem estudadas, devemos começar por questionar como é que essas categorias vieram a ser agenciadas de maneiras diferentes em diferentes espaços e tempos, e com que efeitos. Os espaços de política nacional não devem ser entendidos "em termos de coordenadas a priori - um palco fixo sobre o qual os eventos ocorrem - mas sim como algo formado

Práxis Educativa, Ponta Grossa, v. 17, e2220018, p. 1-21, 2022 Disponível em: <https:/ /revistas2.uepg.br/index.php/praxiseducativa> 
por relaģões entre partes heterogêneas" (Savage \& Lewis, 2018, p. 137, ênfase no original), relações que normalmente atravessam e vão além dos espaços políticos nacionais de maneiras complexas (Temenos \& McCann, 2013). Qualquer política nacional, portanto, pode ser mais bem compreendida como uma reivindicação do que como um fato, e não pode ser compreendida fora dos componentes que realmente a constituem; com tais componentes sempre contingentes e sujeitos a alterações. Como Anderson e MacFarlane (2011) argumentam:

\begin{abstract}
Os agenciamentos sempre "reivindicam" um território à medida que partes heterogêneas são reunidas e mantidas juntas. Mas isso só pode ser um processo provisório: as relações podem mudar, novos elementos podem entrar, alianças podem ser quebradas, novas conjunções podem ser fomentadas. Os agenciamentos se abrem constantemente para novas linhas de fuga, novos devires. (p. 126)
\end{abstract}

Com tudo isso em mente, faz sentido que uma abordagem sobre o agenciamento convide os pesquisadores a prestar forte atenção à política e às capacidades relativas de indivíduos e de organizações para exercer a agência em relação tanto à criação de políticas quanto à sua promulgação. A própria noção do agenciamento de políticas traz consigo um foco em várias formas de processo, ou seja, os muitos atos de montagem e de agrupamento que ocorrem para criar formas de coerência a partir da multiplicidade com a esperança de orientar os indivíduos e grupos para fins particulares. Para compreender os processos do agenciamento de políticas, é difícil não focar no papel de vários atores e agentes na criação das condições de possibilidade para o surgimento de certas políticas, ao mesmo tempo em que obscurece as possibilidades de fazer política de outra forma. $\mathrm{Li}$ (2007), por exemplo, coloca um forte foco na agência e no papel que os atores políticos e as organizações desempenham em processos altamente contestados de elaboração e de execução de políticas. As sugestões de Li (2007) sobre agenciamento implicitamente "destaca a agência" (p. 264) e o trabalho complexo envolvido em compor e sustentar conexões entre componentes na esperança de manter a coerência necessária para governar. Com relação aos processos de desenvolvimento de políticas, Li (2007) sugere que uma prática central que precisa ser compreendida pelos pesquisadores é a da problematização: isto é, "como os problemas passam a ser definidos como problemas em relação a esquemas particulares de pensamento, diagnósticos de deficiência e promessas de melhoria" (p. 264). Crucial aqui é como "certos tipos de problemas e soluções se tornam pensáveis enquanto outros são submersos" (p. 386). Dessa forma, uma abordagem sobre o agenciamento fala produtivamente com outros trabalhos que se baseiam em perspectivas foucaultianas (Bacchi, 2012; Webb, 2014). Savage e Lewis (2018) argumentam que a problematização também requer muita atenção em como diferentes contextos políticos e políticas fornecem diferentes condições de possibilidade para a política emergir de maneiras diferentes, argumentando: "certos contextos políticos fornecem condições favoráveis a certas ideias e práticas políticas, mas não outros, e a agência de atores e organizações de políticas, e a fidelidade das propostas de políticas, é, portanto, sempre 'situada' e dependente do contexto" (p. 125). Diferentes espaços e tempos, criam, desse modo, diferentes potencialidades (McFarlane, 2011).

Ao mesmo tempo, é necessária atenção à fase de promulgação da política, especialmente à forma como os atores interagem com a política, às vezes permitindo e às vezes subvertendo os objetivos da política. Como Baker e McGuirk (2017) argumentam, as "metodologias do agenciamento" não estão apenas "comprometidas em revelar os trabalhos que produzem e mantêm os agenciamentos: os trabalhos de agenciar" (p. 431); mas igualmente como os agenciamentos são mantidos juntos ou sujeitos a formas de perturbação e mudança. Isso é especialmente importante no campo da pesquisa sobre mobilidade política. Como argumentam Temenos e McCann (2013), as políticas não apenas "se movem em algum sentido abstrato", mas sim "as pessoas as movem para propósitos específicos" (p. 344; ênfase no original); o que significa que é necessária uma atenção especial ao papel de tais atores no contorno da forma dos movimentos políticos e das promulgações subsequentes. A análise de Ureta (2015) do desenvolvimento e da promulgação do

Práxis Educativa, Ponta Grossa, v. 17, e2220018, p. 1-21, 2022 Disponível em: <https://revistas2.uepg.br/index.php/praxiseducativa> 
sistema de transporte público Transantiago em Santiago é ilustrativa de um compromisso em traçar o papel de vários seres humanos - ou "dispositivos humanos" (p. 4) - na elaboração e na execução de políticas. Ureta examina o desenvolvimento da reforma da infraestrutura desde sua proposta inicial em 2000 até seu lançamento em 2007 e seus impactos resultantes (muitas vezes negativos) até 2009. Ao fazê-lo, ele presta atenção específica aos papéis de vários atores, desde designers gráficos contratados para promover a nova política e os acadêmicos e cidadãos utilizados para vender os méritos da reforma, até os servidores públicos encarregados de gerenciar e reparar as promulgações políticas fracassadas e os usuários de transporte que se envolveram e, muitas vezes, resistiram à reforma. Ureta (2015) posiciona os humanos como sempre imbuídos de agência, com "a capacidade de alterar o estado atual das coisas de uma maneira ou de outra" (p. 7). Usando ideias de Foucault, Nikolas Rose e outros teóricos da governamentalidade, Ureta (2015) enquadra os humanos como sujeitos governados e autogovernados: isto é, sujeitos da política, mas também agentes resistivos ativos. Ao fazê-lo, ele introduz o termo "coisas estranhas" (p. 10), que ele adapta do trabalho de Marres (2005) para capturar os muitas vezes inesperados "transbordamentos" (Ureta, 2015, p. 8), isto é, os efeitos inesperados, que resultam da tensão entre os sujeitos sendo governados e os indivíduos que buscam se autogovernar e exercer agência. Ureta (2015) também se baseia centralmente em ideias do campo da teoria ator-rede, que tem sido central para o desenvolvimento de abordagens do agenciamento de políticas e que mantém um forte foco em agentes humanos e não humanos (ver também Gorur, 2011; Koyama, 2015; Latour, 2005).

Em última análise, ao dedicar atenção aos complexos canais de poder, política e agência que delineiam as possibilidades de criação e de promulgação de políticas, uma abordagem sobre o agenciamento sinaliza ricas oportunidades para pesquisas críticas impulsionadas por visões normativas sobre como podemos fazer melhor as políticas no futuro. Por exemplo, ao se envolver em uma análise de como diferentes partes componentes tornam certas políticas possíveis, os pesquisadores não estão apenas bem posicionados para compor formas sofisticadas de resistência, mas também para imaginar como poderíamos fazer políticas de outra forma: isto é, considerar como novos e diferentes conjuntos podem ser forjados com impactos e possibilidades potencialmente mais positivos, isto é, novas formas de emergência. Com base em Peck (2011), uma abordagem sobre o agenciamento não apenas ajuda a ver como a própria política é "saturada por relações de poder" (p. 791), mas mostra como qualquer agenciamento sempre traz em si as sementes da mudança potencial (ver também Tampio, 2009). Como McFarlane (2011) argumenta, ao "enfatizar o potencial através de sua orientação para agenciar, reagenciar e constituir, o agenciamento foca nas disjunções entre o real e o possível", posicionando-se, assim, para considerar "como as relações poderiam ser agenciadas de outra forma" (p. 210). Acuto e Curtis (2014) trazem um ponto semelhante ao argumentarem que o pensamento do agenciamento traz consigo uma orientação política clara, sugerindo que "o compromisso com a crítica encontrado no trabalho do agenciamento é em si uma orientação política" (p. 12), acrescentando: "o agenciamento é carregado de possibilidades críticas e políticas" e levanta "novas questões sobre a natureza do poder" (p. 13). É claro que isso não significa que devemos sempre ver os agenciamentos como forças negativas que invariavelmente devem ser resistidas. Afinal, como argumenta Legg (2011), a composição do agenciamento muitas vezes pode ser generativa e positiva, observando:

É claro que há necessidade de ordenação, segurança e estratificação, e esses processos poderosos não precisam ser negativos. Um movimento sindical, uma família, uma parceria, uma migração ou uma linha de demarcação precisam de algum grau de controle, mas isso pode ser produtivo e não dedutivo. (p. 129, ênfase no original).

Dessa forma, os agenciamentos não devem ser vistos simplesmente como captadores ou determinantes de forças, mas sempre como espaços maduros de potencialidade e de mudança, sempre abrindo novas janelas e linhas de fuga para imaginar e montar algo melhor de acordo com alguma visão normativa preferida do mundo.

Práxis Educativa, Ponta Grossa, v. 17, e2220018, p. 1-21, 2022 Disponível em: < https://revistas2.uepg.br/index.php/praxiseducativa $>$ 


\section{Levando o agenciamento de políticas em frente}

Anderson e MacFarlane (2011) argumentam que "parte da razão pela qual o agenciamento está sendo cada vez mais usado em um amplo espectro de contextos é sua própria manipulação", sugerindo que é usado de várias maneiras como um descritor, um conceito e um ethos de modos que muitas vezes diferem em forma e efeito, o que por sua vez, produz complexas "diferenças e tensões" (p. 126) em como o termo é articulado e posto em prática. Essa manipulação do agenciamento traz riscos evidentes. Quando um termo é camaleônico, disposto a significar muitas coisas, pode acabar significando tudo e qualquer coisa e, logo, nada ao mesmo tempo. Igualmente preocupante é o argumento de Allen (2011) de que a pesquisa com o agenciamento muitas vezes falha em se estender além do rastreamento "fino" e da descrição de várias partes componentes. Se o agenciamento continuar a servir dessa maneira, como pouco mais do que uma justificativa para um mapeamento elaborado de vários pedaços de política, acabará por perder poder explicativo (Brenner et al., 2011) e será incapaz de abordar o rico potencial para explorar questões mais profundas sobre política, poder e agência que o conceito oferece; um potencial para formular visões de um futuro melhor. É importante, portanto, evitar que o agenciamento escorregue para um labirinto conceitual.

Este trabalho procurou responder a tais riscos. Ao sintetizar os eixos centrais da literatura existente, foram identificados três fundamentos teóricos e conceituais centrais para uma abordagem sobre o "agenciamento de políticas": (1) relações de exterioridade e emergência; (2) heterogeneidade, relacionalidade e fluxo; e (3) atenção ao poder, à política e à agência. Juntos, esses fundamentos são vistos aqui como sinalizando uma coerência do pensamento sobre agenciamento, o que sugere que uma abordagem sobre o agenciamento tem um potencial poderoso, permitindo que os pesquisadores vejam e expliquem as coisas de maneiras que muitas tradições estabelecidas na pesquisa de políticas não conseguem. Ao identificar os fundamentos e oferecer exemplos de como cada um pode ser mobilizado, o artigo procurou fornecer o início de um arcabouço para a pesquisa sobre o agenciamento de políticas ainda não articulado de forma sistemática, convidando assim a uma discussão mais aprofundada sobre o que significa fazer tal pesquisa. Ao fazê-lo, não foi a intenção sugerir que o agenciamento deveria ter um significado fixo ou ser ancorado exclusivamente no trabalho de alguns pesquisadores (Allen, 2011; Anderson \& MacFarlane, 2011). Tampouco a intenção foi sugerir que os três fundamentos articulados anteriormente devam constituir qualquer tipo de palavra final sobre as características centrais de uma abordagem sobre o agenciamento. Em vez disso, o artigo serve como um convite para o engajamento em uma discussão mais aprofundada sobre uma abordagem da pesquisa de políticas e como pode ser rica em possibilidades.

Embora este artigo tenha se engajado em uma descompactação detalhada dos fundamentos teóricos e analíticos de uma abordagem sobre o agenciamento para análise de políticas, é claro que é necessário mais trabalho para articular quais podem ser os fundamentos metodológicos de tal abordagem. Como Baker e McGuirk (2017) argumentam, embora existam "muitos relatos usando metodologias influenciadas por agenciamento de vários tipos como ferramentas analíticas para revelar, interpretar e representar os mundos da formulação de políticas", também é verdade que "poucos são explícitos sobre sua prática metodológica" (p. 425). O caminho a seguir, portanto, não está apenas em estabelecer mais clareza sobre os tipos de práticas metodológicas que associamos ao agenciamento, mas em reuní-las de maneira coerente e convincente com os tipos de fundamentos teóricos e conceituais que o artigo procurou articular acima. Somente por meio dessas práticas de síntese uma teoria sobre agenciamento será capaz de garantir o nível de "conceitualização pensada" (Allen, 2011, p. 156) necessário para que pesquisadores defendam produtivamente e ampliem seu uso na pesquisa sobre políticas.

Práxis Educativa, Ponta Grossa, v. 17, e2220018, p. 1-21, 2022

Disponível em: <https://revistas2.uepg.br/index.php/praxiseducativa> 


\section{DECLARAÇÃO DE CONFLITO DE INTERESSE}

Nenhum potencial conflito de interesse foi relatado pelo autor.

\section{FINANCIAMENTO}

Este trabalho foi financiado pelo Australian Research Council [Processo n ${ }^{\circ}$ DE160100197].

\section{ORCID}

Glenn C. Savage http://orcid.org/0000-0001-6495-6798

\section{Referências}

Acuto, M., \& Curtis, S. (2014). Reassembling international theory: Assemblage thinking and international relations. London: Palgrave Macmillan.

Allen, J. (2009). Three spaces of power: Territory, networks, plus a topological twist in the tale of domination and authority. Journal of Power, 2, 197-212.

Allen, J. (2011). Topological twists: Power's shifting geographies. Dialogues in Human Geography, 1(3), 283-298.

Allen, J., \& Cochrane, A. (2010). Assemblages of state power: Topological Shifts in the Organization of government and politics. Antipode, 42(5), 1071-1089.

Amin, A. (2002). Spatialities of globalisation. Environment and Planning A, 34, 385-399.

Anderson, B., \& MacFarlane, C. (2011). Assemblage and geography. Area, 43(2), 124-127.

Bacchi, C. (2012). Why study Problematizations? Making politics visible. Open Journal of Political Science, 2(1), 1-8.

Baker, T., \& McGuirk, P. (2017). Assemblage thinking as methodology: Commitments and practices for critical policy research. Territory, Politics, Governance, 5(4), 425-442.

Brenner, N., Madden, D. J., \& Wachsmuth, D. (2011). Assemblage urbanism and the challenges of critical urban theory. City, 15(2), 225-240.

Buchanan, I. (2015). Assemblage theory and Its Discontents. Deleure Studies, 9(3), 382-392.

Buchanan, I. (2017). Assemblage theory, or, the future of an illusion. Deleuze Studies, 11(3), 457474.

Bueger, C. (2014). Thinking assemblages methodologically: Some rules of thumb. In M. Acuto, \& S. Curtis (Eds.), Reassembling international theory: Assemblage thinking and international relations (pp. 5866). London: Palgrave Macmillan.

Clarke, J., Bainton, D., Lendvai, N., \& Stubbs, P. (2015). Making policy move: Towards a politics of translation and assemblage. Bristol: Policy Press. 
DeLanda, M. (2006). A new philosophy of society: Assemblage theory and social complexity. London: Continuum.

DeLanda, M. (2016). Assemblage theory. Edinburgh: Edinburgh University Press.

Deleuze, G. (1992). What is a dispositif? In T. J. Armstrong (Ed.), Michel Foucault Philosopher (pp. 159-168). London: Harvester Wheatsheaf.

Deleuze, G. (2002). Dialogues II. London: Continuum.

Deleuze, G., \& Guattari, F. (1987). A thousand plateaus: Capitalism and schizophrenia. Translated by Brian Massumi. Minneapolis: University of Minnesota Press.

Dunn, E. C. (2005). Standards and person-making in East central Europe. In A. Ong, \& C. Collier (Eds.), Global assemblages: Technology, politics, and ethics as anthropological problems (pp. 173-193). Malden: Blackwell.

Foucault, M. (1980). The history of sexuality, Vol. 1: An introduction. New York: Vintage.

Foucault, M. (2007). Security, territory, population: Lectures at the College de France, 1977-1978. Basingstoke: Palgrave MacMillan.

Foucault, M. (2008). The Birth of Biopolitics: Lectures at the College de France, 1978-1979. Translated by Graham Burchell. London: Palgrave.

Geyer, R., \& Rihani, S. (2010). Complexity and public policy: A new approach to 21 st century politics, policy and society. London: Routledge.

Gorur, R. (2011). Policy as assemblage. European Educational Research Journal, 10(4), 611-622.

Gulson, K. N., Lewis, S., Lingard, B., Lubienski, C., Takayama, K., \& Webb, P. T. (2017). Policy mobilities and methodology: A proposition for inventive methods in education policy studies. Critical Studies in Education, 58(2), 224-241.

Hartong, S. (2018). Towards a topological re-assemblage of education policy? Observing the implementation of performance data infrastructures and 'centers of calculation' in Germany. Globalisation, Societies and Education, 16(1), 134-150.

Hayden, P. (1995). From relations to practice in the empiricism of Gilles Deleuze. Man and World, 28, 283-302.

Kingfisher. (2016). A policy travelogue: Tracing Welfare reform in Aotearoa/New Zealand and Canada. New York: Berghahn.

Koyama, J. (2015). When things come undone: The promise of dissembling education policy. Discourse: Studies in the Cultural Politics of Education, 36(4), 548-559.

Latour, B. (2005). Re-assembling the social: An introduction to actor-network theory. Oxford: Oxford University Press.

Law, J. (1994). Organižing modernity. Oxford: Blackwell.

Legg, S. (2011). Assemblage/apparatus: Using Deleuze and Foucault. Area, 43(2), 128-133. 
Lewis, S. (2017). Governing schooling through 'what works': The OECD's PISA for schools. Journal of Education Policy, 32(3), 281-302.

Lewis, S., \& Lingard, B. (2015). The multiple effects of international large-scale assessment on education policy and research. Discourse: Studies in the Cultural Politics of Education, 36(5), 621-637.

Li, T. M. (2005). Beyond "the state" and failed schemes. American Anthropologist, 107(3), 383-394.

Li, T. M. (2007). Practices of assemblage and community forest management. Economy and Society, 36(2), 263-293.

Lingard, B., Sellar, S., \& Savage, G. C. (2014). Rearticulating social justice as equity in schooling policy: The effects of testing and data infrastructures. British Journal of Sociology of Education, 35(5), $710-730$.

Lury, C., Parisi, L., \& Terranova, T. (2012). Introduction: The becoming topological of culture. Theory, Culture and Society, 29(4-5), 3-35.

Marres, N. (2005). No issue, no public: Democratic deficits after the displacement of politics. Amsterdam: University of Amsterdam.

McCann, E., \& Ward, K. (eds.). (2011). Mobile urbanism: Cities and policymaking in the global age. Minneapolis: University of Minnesota Press.

McCann, E., \& Ward, K. (2012). Policy assemblages, mobilities, and mutations: Toward a multidisciplinary conversation. Political Studies Review, 10(3), 325-332.

McCann, E., \& Ward, K. (2013). A multi-disciplinary approach to policy transfer research: Geographies, assemblages, mobilities and mutations. Policy Studies, 34(1), 2-18.

McFarlane, C. (2011) Assemblage and critical urbanism. City, 15(2), 204-224.

Miller, P., \& Rose, N. (2008). Governing the present: Administering economic, social and personal life. Cambridge: Polity Press.

Nail, T. (2015). The figure of the migrant. Stanford: Stanford University Press.

Nail, T. (2017). What is an assemblage? SubStance, 46(1), 21-37.

Ong, A. (2014). The carpenter and the bricoleur. In M. Acuto, \& S. Curtis (Eds.), Reassembling international theory: Assemblage thinking and international relations (pp. 17-24). London: Palgrave Macmillan.

Ong, A., \& Collier, S. J. (2005). Global assemblages: Technology, politics and ethics as anthropological problems. Malden: Blackwell.

Parkhurst, J. (2017). The politics of evidence: From evidence-based policy to the good governance of evidence. New York: Routledge.

Peck, J. (2011). Creative moments: Working culture, through municipal socialism and neoliberal urbanism. In Mobile urbanism: Cities \& policy-making in the global age (pp. 41-70). Minneapolis: University of Minnesota Press.

Peck, J., \& Theodore, N. (2015). Fast policy. Minneapolis: University of Minnesota Press. 
Prince, R. (2010). Policy transfer as policy assemblage: Making policy for the creative industries in New Zealand. Environment and Planning A, 42, 169-186.

Prince, R. (2017). Local or global policy? Thinking about policy mobility with assemblage and topology. Area, 49(3), 335-341.

Rabinow, P. (2014). Assembling untimeliness: Permanently and resistively. In J. Faubion (Ed.), Foucault now: Current perspectives in Foucault studies (pp. 203-224). Cambridge: Polity Press.

Ruppert, E. (2012). The Governmental topologies of Database devices. Theory, Culture and Society, 29(4-5), 116-136.

Sassen, S. (2014). The carpenter and the bricoleur. In M. Acuto, \& S. Curtis (Eds.), Reassembling international theory: Assemblage thinking and international relations (pp. 17-24). London: Palgrave Macmillan.

Savage, G. C. (2018). Policy assemblages and human devices: A reflection on 'assembling policy'. Discourse: Studies in the Cultural Politics of Education, 39(2), 309-321.

Savage, G. C., \& Lewis, S. (2018). The phantom national? Assembling national teaching standards in Australia's federal system. Journal of Education Policy, 33(1), 118-142.

Shore, C., Wright, S., \& Pero, D. (2011). Conceptualising policy: Technologies of governance and the politics of Visibility. In C. Shore, S. Wright, \& D. Pero (Eds.), Policy worlds: Anthropology and the analysis of contemporary power (pp. 1-26). New York: Berghahn.

Tampio, N. (2009). Assemblages and the Multitude: Deleuze, Hardt, Negri, and the Postmodern Left. European Journal of Political Theory, 8(3), 383-400.

Temenos, C., \& McCann, E. (2013). Geographies of policy mobilities. Geography Compass, 7(5), 344357.

Thompson, G., \& Cook, I. (2015). Becoming-topologies of education: Deformations, networks and the database effect. Discourse: Studies in the Cultural Politics of Education, 36(5), 732-748.

Ureta, S. (2015). Assembling policy: Transantiago, buman devices, and the dream of a world class society. Cambridge, MA: MIT Press.

Urry, J. (2003). Global complexity. Cambridge: Polity.

Webb, T. (2014). Policy problematization. International Journal of Qualitative Studies in Education, 27(3), 364-376.

Youdell, D., \& McGimpsey, I. (2015). Assembling, disassembling and reassembling 'youth services' in Austerity Britain. Critical Studies in Education, 56(1), 116-130.

Autorização de publicação recebida em 26/01/2022

Publicado online em 04/02/2022

Práxis Educativa, Ponta Grossa, v. 17, e2220018, p. 1-21, 2022 